\title{
Caudatin inhibits human hepatoma cell growth and metastasis through modulation of the Wnt/ $\beta$-catenin pathway
}

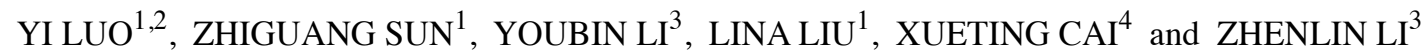 \\ ${ }^{1}$ Institute of First Clinical Medicine, Nanjing University of Chinese Medicine, Nanjing, Jiangsu 210046; \\ ${ }^{2}$ Department of Oncology, Jiangsu Province Hospital on Integration of Chinese and Western Medicine, Nanjing, \\ Jiangsu 210028; Laboratories of ${ }^{3}$ Traditional Chinese Medicine Chemistry, ${ }^{4}$ Cellular and Molecular Biology, \\ Jiangsu Province Institute of Traditional Chinese Medicine, Nanjing, Jiangsu 210028, P.R. China
}

Received July 12, 2013; Accepted August 27, 2013

DOI: $10.3892 /$ or.2013.2749

\begin{abstract}
In the present study, we investigated the antitumor activity of caudatin in the human hepatoma cell line SMMC-7721 by analysis of cell viability, cell cycle distribution, apoptosis and metastasis. The results showed that caudatin impaired the cell viability and inhibited the growth of SMMC-7721 cells in a time- and dose-dependent manner and resulted in cell cycle arrest in the G2 phase. In addition, SMMC-7721 cells, treated with caudatin exhibited typical characteristics of apoptosis. Furthermore, caudatin treatment resulted in a decrease in $\beta$-catenin and GSK3 $\beta$ in SMMC-7721 cells, with a concomitant reduction in metastatic capability and expression of Wnt signaling pathway targeted genes including cox-2, $m m p-2$ and $m m p-9$. Our findings revealed that caudatin inhibits human hepatoma cell growth and metastasis by targeting the GSK $3 \beta / \beta$-catenin pathway and suppressing VEGF production.
\end{abstract}

\section{Introduction}

Approximately $80-90 \%$ of primary liver cancers are hepatocellular carcinomas (HCCs). HCC is one of the three most common types of tumors worldwide apart from gastric and esophageal cancer. More than one million individuals are newly diagnosed with liver cancer each year. China is the country with the highest incidence of liver cancer. Therapeutic approaches for the treatment of HCC can be classified into three categories: potentially curative, palliative and symptomatic. Although liver cancer can be surgically removed, the 2 -year recurrence rate is as high as $50 \%$. In the past 20 years, the relative 5-year survival rate of patients with liver cancer has increased by $3 \%$ from 4 to $7 \%$ (1). Moreover, due to under-

Correspondence to: Professor Zhiguang Sun, Institute of First Clinical Medicine, Nanjing University of Chinese Medicine, 282 Hanzhong Road, Nanjing, Jiangsu 210046, P.R. China

E-mail: robertluoyi@126.com

Key words: caudatin, human hepatoma cells, cell growth, metastasis, Wnt, $\beta$-catenin lying cirrhosis, systemic therapy with classical cytotoxic drugs is poorly tolerated and ineffective. Sorafenib was approved by the FDA for the treatment of unresectable HCC and was recommended as the first-line therapy for HCC patients who cannot benefit from therapies that are potentially more effective, such as TACE or local ablative therapy (2). A subanalysis was conducted to assess the multiple risk factors involved in HCC oncogenesis, and this revealed that sorafenib can also be beneficial for patients with alcohol-related HCC or hepatitis B or hepatitis C infection (3). Despite improvements in survival after sorafenib administration, the prognosis for patients with this stage of HCC is still poor, with a median overall survival rate of 6.5-10.7 months (4). Accordingly, there is an urgent need to identify new therapeutic agents for the treatment of hepatoma in clinical practice.

Chinese medicine has achieved satisfactory results in the treatment of liver cancer, by improving symptoms and quality of life, and preventing recurrence and metastasis. Chemotherapy agents commonly used in many clinical anticancer compounds are extracted from herbal or animal substances $(5,6)$. The root of Cynanchum auriculatum Royle ex Wight, a traditional Chinese medicine, has been used to nourish the blood and enhance immunity in China and other Asian countries for a long time. C-21 steroidal glycosides is one species of important biological active compounds widely found in the plants of the Asclepiadaceae family, which has been shown to effectively remove hydroxyl radicals and oxygen free radicals, regulating immunity, and protecting liver and nerve cells $(7,8)$. To date, many types of C-21 steroidal glycosides have been purified from Cynanchum bungei Decne. For example, caudatin, one species of C-21 steroidal, has been mainly isolated from the root of Cynanchum bungei Decne in China. The chemical structure of caudatin is shown in Fig. 1. Although studies have shown that caudatin induces apoptosis in SMMC-7721 cells (9), the underlying mechanisms of its action are not completely understood. The purpose of the present study was to determine the effects of caudatin on SMMC-7721 cell growth and metastasis and to investigate the possible molecular mechanisms. Our results showed that caudatin modulated Wnt/ $\beta$-catenin signaling and inhibited cell proliferation and induced cell apoptosis in SMMC-7721 cells. In addition, a non-toxic dose of caudatin suppressed 


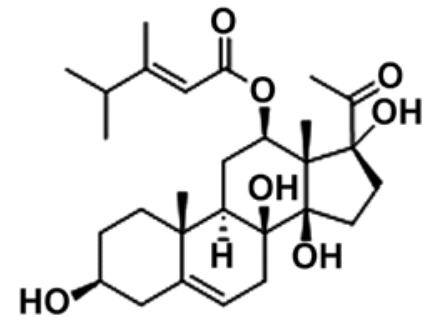

Figure 1. Chemical structure of caudatin $\left(\mathrm{C}_{28} \mathrm{H}_{42} \mathrm{O}_{7}\right.$; CAS no. 38395-02-7; Mol. Wt. 490.633).

the migration of SMMC-7721 cells through the inhibition of MMP-2, MMP-9 and VEGF secretion.

\section{Materials and methods}

Materials. Caudatin (95.6\% purity) was isolated from the root tuber of Cynanchum auriculatum by our research group (10). Caudatin was dissolved in dimethyl sulfoxide (DMSO) and was used in all experiments. MTT [3-(4,5-dimethylthiazol2-yl)-2,5-diphenyltetrazolium bromide] was obtained from Sigma (St. Louis, MO, USA). Lysis buffer was purchased from Beyotime Institute of Biotechnology (Haimen, China). Antibodies (GSK3 $\beta$, COX-2, MMP-2, MMP-9, GAPDH and goat anti-rabbit IgG-HRP) were obtained from BioWorld (Dublin, OH, USA). $\beta$-catenin was obtained from Proteintech (Chicago, IL, USA). VEGF was purchased from Santa Cruz Biotechnology (Santa Cruz, CA, USA).

Cell culture. Human hepatoma cell line SMMC-7721 was purchased from the Cell Bank of Xiangya Central Experimental Laboratory. Cells were cultured in RPMI-1640 medium supplemented with $10 \%$ fetal bovine serum (FBS), $100 \mathrm{U} / \mathrm{ml}$ penicillin and $100 \mu \mathrm{g} / \mathrm{ml}$ streptomycin (all available from Invitrogen, Grand Island, NY, USA).

Cytotoxicity assay. The cytotoxic effect of caudatin on SMMC-7721 cells was analyzed by MTT assay. SMMC7721 cells at mid-log phase were seeded in a 96-well plate at a density of $5 \times 10^{3}$ cells/well in $100 \mu 1$ medium. After a 24-h incubation, cells were exposed to $0.1 \%$ DMSO (used as control in all experiments) or 15, 30, 60, 90 and $120 \mu \mathrm{M}$ caudatin for 24,48 and $72 \mathrm{~h}$. After treatment, $20 \mu \mathrm{l}$ of $5 \mathrm{mg} / \mathrm{ml}$ MTT was added, and the cells were incubated for $4 \mathrm{~h}$ at $37^{\circ} \mathrm{C}$. The supernatant was discarded, and $150 \mu \mathrm{l}$ of DMSO was added to each well. The mixture was shaken on a mini shaker at room temperature for $10 \mathrm{~min}$, and the spectrophotometric absorbance was measured using the Multiskan Spectrum microplate reader (Thermo Fisher Scientific, Waltham, MA, USA) at 490 and $630 \mathrm{~nm}$ (absorbance $490 \mathrm{~nm}$, reference $630 \mathrm{~nm}$ ). Triplicate experiments were performed in a parallel manner for each concentration, and the results are presented as means $\pm \mathrm{SD}$. The net $\mathrm{OD}_{490 \mathrm{~nm}}-\mathrm{OD}_{630 \mathrm{~nm}}$ was taken as the index of cell viability. The net absorbance from the wells of cells cultured with DMSO was taken as the $0 \%$ inhibitory rate. The percent inhibitory rate (IR \%) of the treated cells was calculated by the formula: IR $\%=1-\left(\mathrm{OD}_{490 \mathrm{~nm}}-\mathrm{OD}_{630 \mathrm{~nm}}\right)$ treated/ $\left(\mathrm{OD}_{490 \mathrm{~nm}}-\mathrm{OD}_{630 \mathrm{~nm}}\right)$ control x $100 \%$.
Cell cycle analysis. Cell cycle distribution was determined using a cell cycle staining kit (Multisciences, USA). Cells treated with $0.1 \%$ DMSO or increasing concentrations of caudatin $(12.5,25$ and $50 \mu \mathrm{M})$ for $48 \mathrm{~h}$ were trypsinized and washed twice with PBS, and fixed in $75 \%$ ethanol overnight at $-20^{\circ} \mathrm{C}$. The fixed cells were washed with PBS twice before incubation with $1 \mathrm{ml}$ Reagent A for $30 \mathrm{~min}$ at $37^{\circ} \mathrm{C}$. DNA content and the cell cycle were determined using a FACScan laser flow cytometer (FACSVerse; Becton-Dickinson, Franklin Lakes, NJ, USA). Data were analyzed using FlowJo software.

Apoptosis assay. SMMC-7721 cells were treated with $0.1 \%$ DMSO or increasing concentrations of caudatin $(12.5,25$ and $50 \mu \mathrm{M}$ ) for $48 \mathrm{~h}$. The cells were then harvested, washed and resuspended with PBS. Apoptotic cells were determined with an Alexa Fluor 488 Annexin V/Dead Cell Apoptosis kit (Invitrogen, Carlsbad, CA, USA) according to the manufacturer's protocol. Briefly, the cells were washed and subsequently incubated for $15 \mathrm{~min}$ at room temperature in the dark in $100 \mu \mathrm{l}$ of $1 \mathrm{X}$ Annexin binding buffer containing $5 \mu 1$ of Annexin V-FITC and $2 \mu \mathrm{l}$ of propidium iodide (PI). Afterward, apoptosis was analyzed using a FACScan laser flow cytometer (FACSVerse). Data were analyzed using FlowJo software.

Transwell assay. The migratory ability of SMMC-7721 cells was examined by Transwell assay. The SMMC-7721 cells with $80 \%$ confluence were washed once with PBS and serum-starved in the basal media (without serum and growth supplements) for $12 \mathrm{~h}$. The harvested cells were counted and reached a volume of $1 \times 10^{6}$ cells $/ \mathrm{ml}$. The cell migration Transwell chamber $(8.0 \mu \mathrm{m} / 6.5 \mathrm{~mm}$; Corning Incorporated, New York, NY, USA) was inserted at an angle of $45^{\circ}$, gently pressed down to avoid generating bubbles, and $100 \mu \mathrm{l}$ of the cell suspension was added to each chamber. DMSO (control) or caudatin $(12.5,25$ and $50 \mu \mathrm{M})$ was added to the cell suspension with $1 \mathrm{ml}$ of fresh medium (10\% FBS) in the lower wells (24-well plate) (Corning Incorporated). After $16 \mathrm{~h}$ of incubation, the cells were fixed and stained. Five randomly chosen fields were counted and photographed using a fluorescence microscope (Leica DM IL).

Western blot analysis. Cells were cultured until mid-log phase and then incubated with different concentrations of caudatin for $24 \mathrm{~h}$. Proteins were isolated by lysis buffer and measured with a BCA protein assay. Protein samples were separated on $10 \%$ SDS-polyacrylamide gels (SDS-PAGE) and transferred onto PVDF membranes (Millipore, Billerica, MA, USA). After being blocked with 1\% BSA in TBST (Tris-buffered saline with Tween-20) for $2 \mathrm{~h}$, membranes were incubated with the primary antibodies overnight at $4^{\circ} \mathrm{C}$. Blots were washed and incubated with the secondary antibodies for $2 \mathrm{~h}$ at room temperature. Membranes were again washed three times with TBST and developed using enhanced chemiluminescence (Beyotime). Membranes were then exposed to film.

Real-time quantitative PCR ( $q P C R)$. Total RNA was extracted using TRIzol reagent (Generay, Shanghai, China) according to the manufacturer's instructions. Total RNA $(2 \mu \mathrm{g})$ was used for cDNA synthesis with random hexamer primers. qPCR was carried out using the CFX Connect Real-Time PCR system. 
Table I. Primer sequences used for real-time quantitative PCR (5'-3').

\begin{tabular}{lll}
\hline Gene & \multicolumn{1}{c}{ Forward primer } & \multicolumn{1}{c}{ Reverse primer } \\
\hline hGAPDH & AGAAGGCTGGGGCTCATTTG & AGGGGCCATCCACAGTCTTC \\
hCOX-2 & AAGACAGATCATAAGCGAGGGC & AAACCGTAGATGCTCAGGGACT \\
hMMP-2 & CTTCAAGGACCGGTTCATTTGG & ATGAGCTTGGGGAAGCCAGGA \\
hMMP-9 & GCGCTGGGCTTAGATCATTC & TCAGGGCGAGGACCATAGAG \\
\hline
\end{tabular}

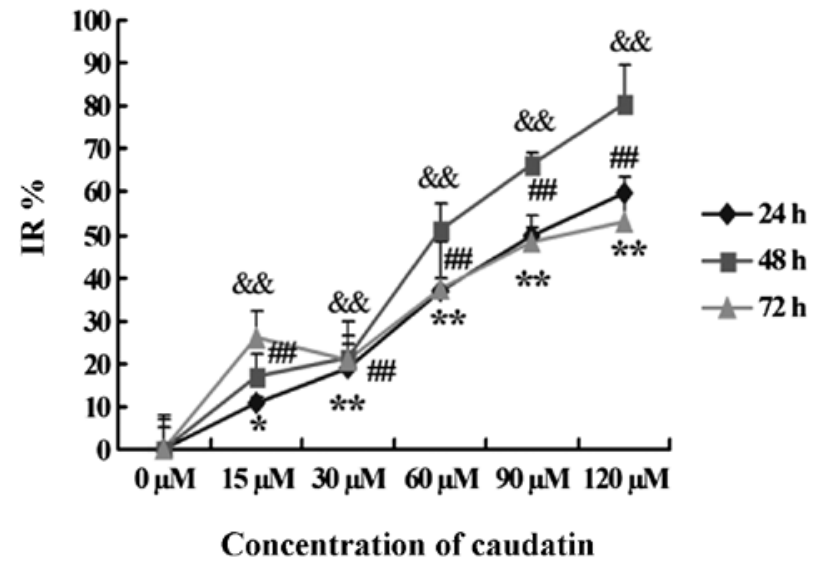

Figure 2. Cytotoxic effect of caudatin on SMMC-7721 cells. The results shown are the mean of three parallel experiments (triplicate wells) for each concentration $(15,30,60,90$ and $120 \mu \mathrm{M})$ at 24,48 and $72 \mathrm{~h} .{ }^{*}$ Indicates $24 \mathrm{~h}$,

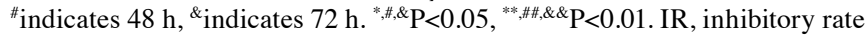

Reactions were performed according to $\mathrm{IQ}^{\mathrm{TM}}$ SYBR Green Supermix instructions (Bio-Rad Laboratories, Hercules, CA, USA) in triplicate in three independent experiments. The primer sequences are provided in Table I. The $\Delta \Delta \mathrm{C}_{\mathrm{T}}$ method was used for qPCR determination. GAPDH was used as a housekeeping gene to normalize the variability in expression levels.

Statistical analysis. All the data are expressed as the means \pm standard deviation (SD). Statistical analysis was performed using the Student's t test, and $\mathrm{P}<0.05$ was considered to indicate a statistically significant result.

\section{Results}

Cytotoxic effect of caudatin on SMMC-7721 cells. The inhibitory effect of caudatin on cell growth was assessed by the commonly used MTT assay at different intervals (24, 48 and $72 \mathrm{~h}$ ) of treatment. Caudatin treatment significantly inhibited the growth of SMMC-7721 cells in both a concentration- and time-dependent manner at 24 and $48 \mathrm{~h}$ (Fig. 2). The inhibitory effect decreased at $72 \mathrm{~h}$, possibly due to drug degradation and cell resistance. The $\mathrm{IC}_{50}$ values at 24,48 and $72 \mathrm{~h}$ were 89.49 , 54.43 and $118.07 \mu \mathrm{M}$. We choose the $48 \mathrm{~h}$ time-point to carry out the follow-up experiments.

Caudatin treatment causes 62 phase cell cycle arrest. To test whether caudatin affects the cell cycle of SMMC-7721 cells, cells treated with DMSO or different concentrations of caudatin
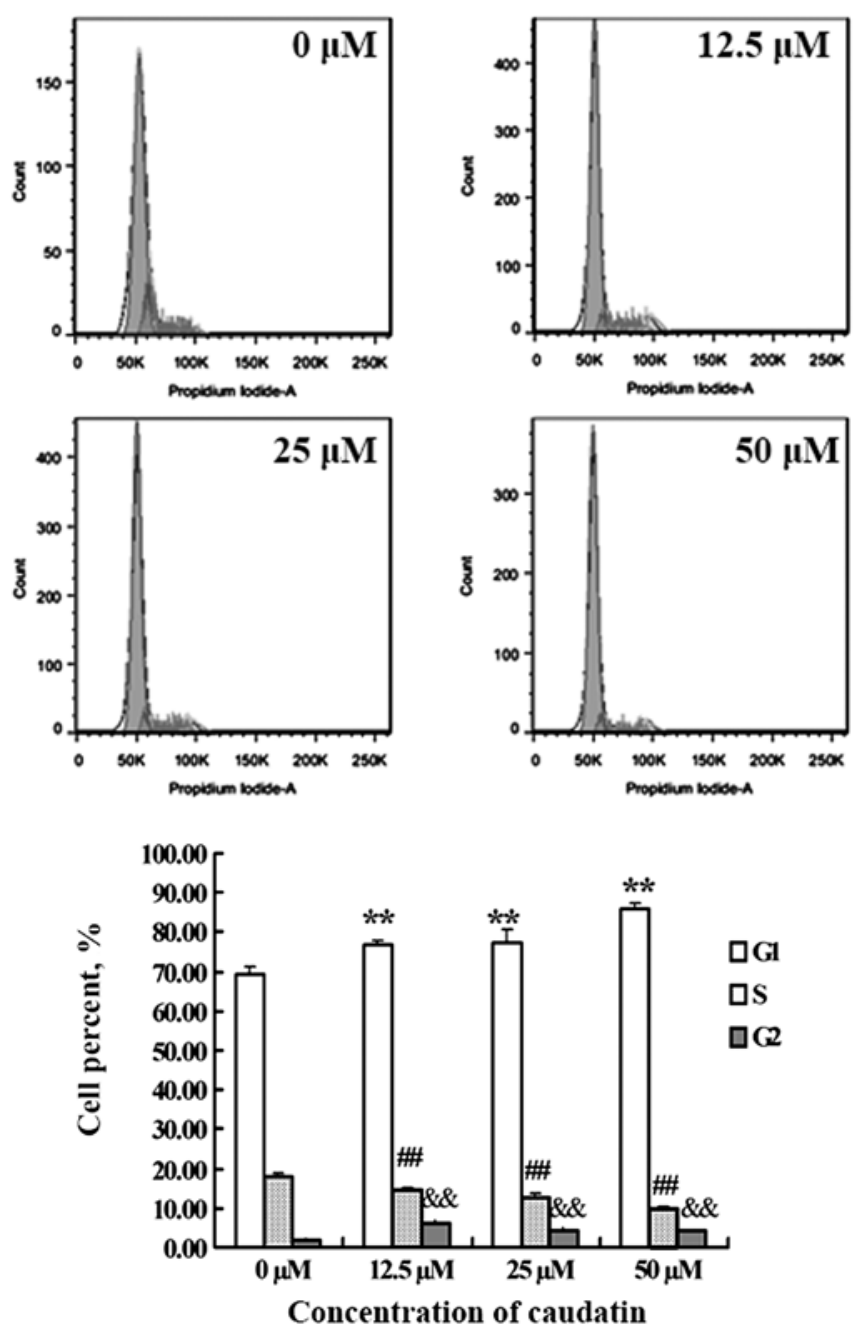

Figure 3. Effect of caudatin on cell cycle distribution in SMMC-7721 cells. Cells were incubated with $0,12.5,25$ and $50 \mu \mathrm{M}$ caudatin for $48 \mathrm{~h}$ and then stained with propidium iodide (PI) for FACS analysis. *Indicates G1, \#indi-

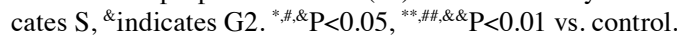

for $48 \mathrm{~h}$ were subjected to flow cytometric analysis after DNA staining. As shown in Fig. 3, exposure of SMMC-7721 cells to growth suppressive concentrations of caudatin resulted in a statistically significant increase in the $\mathrm{G} 2$ phase cell population which was accompanied by a decrease in the $S$ phase population. For example, the percentage of cells in the G2 phase increased by $\sim 2$-fold following the treatment of SMMC-7721 cells with $12.5 \mu \mathrm{M}$ caudatin when compared with the control. This indicated that caudatin suppressed SMMC-7721 cell proliferation associated with cell cycle arrest at the G2 phase. 

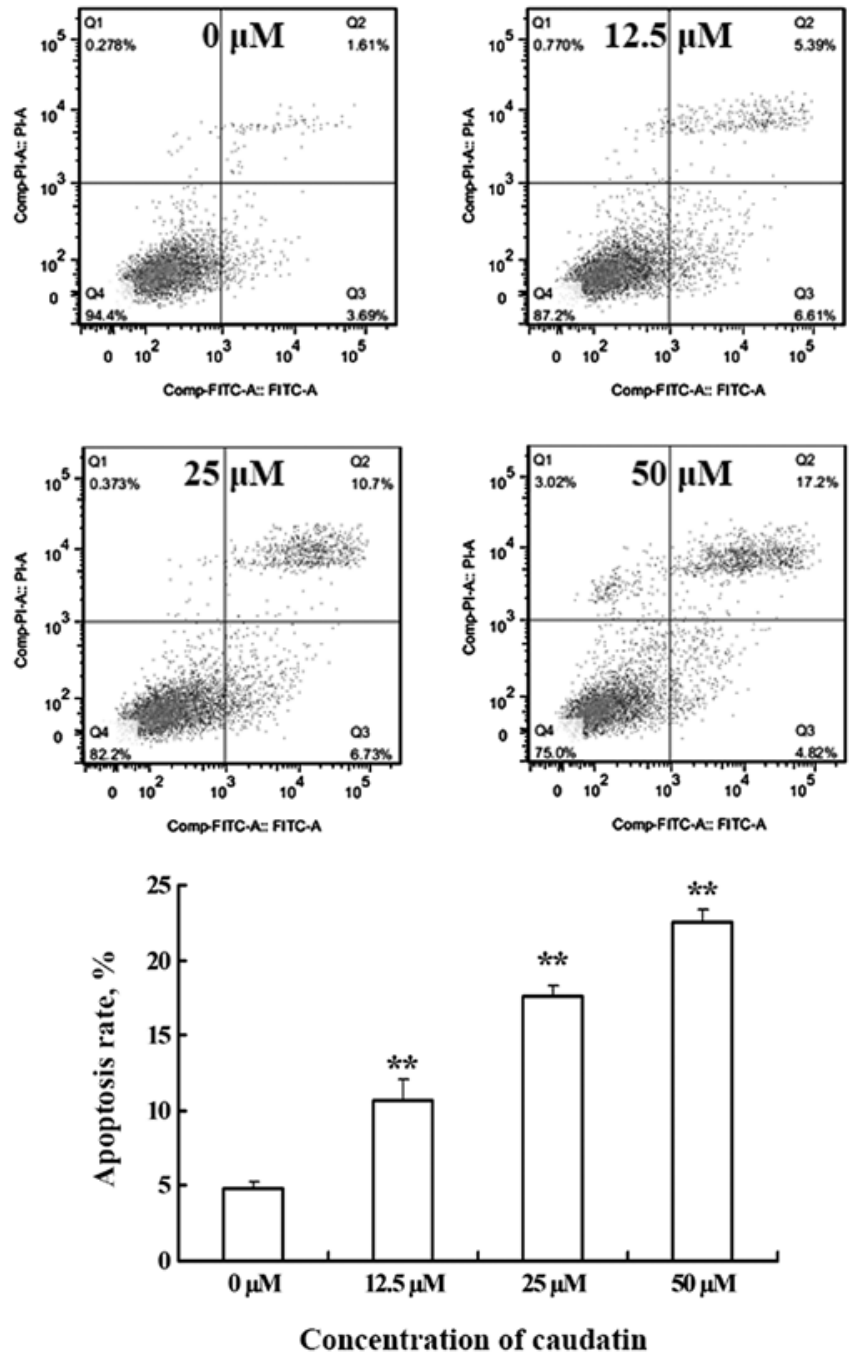

Figure 4. Caudatin induces the apoptosis of SMMC-7721 cells. SMMC-7721 cells were untreated or treated for $48 \mathrm{~h}$ with different concentrations of caudatin. After a 48 -h treatment, $10.67 \pm 1.45 \%$ of the SMMC-7721 cells were in an apoptotic stage $(\mathrm{Q} 2+\mathrm{Q} 3)$ following treatment with $12.5 \mu \mathrm{M}$ caudatin, $17.65 \pm 0.64 \%$ were apoptotic following treatment with $25 \mu \mathrm{M}$ caudatin and $22.52 \pm 0.83 \%$ were apoptotic following treatment with $50 \mu \mathrm{M}$ caudatin. ${ }^{*} \mathrm{P}<0.05,{ }^{* * *} \mathrm{P}<0.01$ vs. control.

Pro-apoptotic effect of caudatin on SMMC-7721 cells. The occurrence of apoptosis was obtained by double staining of the cultures with PI and Annexin V-FITC. Annexin V is a protein that binds with high affinity to phosphatidylserine, which is translocated from the inner to the outer membrane leaflet early in the apoptotic process. As shown in Fig. 4, living cells stained negative for both PI and Annexin V-FITC (Q4). Caudatin-induced cells, on the other hand, showed many Annexin V-positive, PI-negative cells (Q3), indicating that they were at an early stage of apoptosis. The double positive staining of particular cells revealed that these cells were in a late apoptotic stage or were necrotic (Q2). These findings provided strong evidence that caudatin has a pro-apoptosis effect on SMMC-7721 cells.

Caudatin inhibits SMMC-7721 cell migration. The migration of SMMC-7721 cells is a prerequisite for tumor metastasis. We determined the effect of caudatin on SMMC-7721 cell migra-
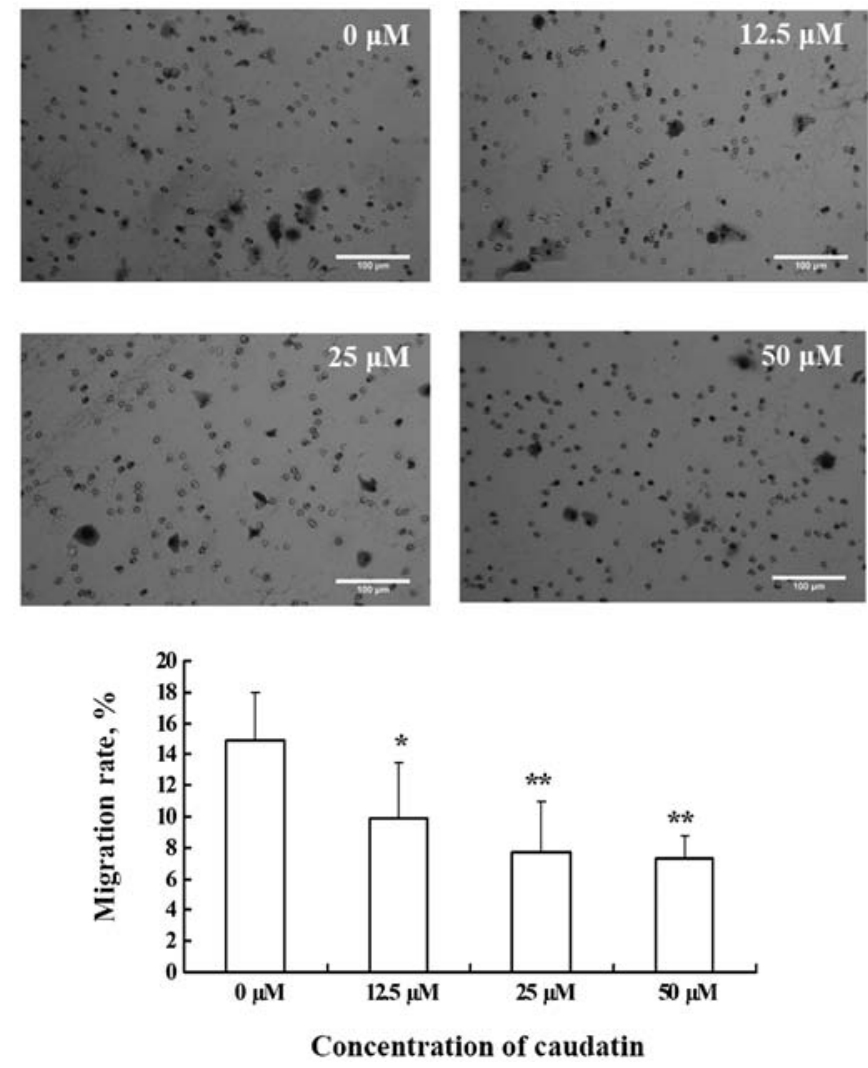

Figure 5. Caudatin inhibits the migration of SMMC-7721 cells. SMMC-7721 cells were untreated or treated for $16 \mathrm{~h}$ with different concentrations of caudatin. After a 16-h treatment, $14.86 \pm 3.08$ of the SMMC-7721 cells had migrated to the lower side of the Transwell filter in the control group, $9.86 \pm 3.58$ cells had migrated following treatment with $12.5 \mu \mathrm{M}$ caudatin, $7.71 \pm 3.25$ cells had migrated following treatment with $25 \mu \mathrm{M}$ caudatin and $7.29 \pm 1.50$ cells had migrated following treatment with $50 \mu \mathrm{M}$ caudatin. ${ }^{*} \mathrm{P}<0.05,{ }^{* *} \mathrm{P}<0.01$ vs. control. Scale bar, $100 \mu \mathrm{m}$.

tion stimulated with FBS using the Boyden Chamber assay. After stimulation for $16 \mathrm{~h}$, a high number of cells migrated to the lower side of the Transwell filter in the control group. However, addition of caudatin to the top chamber significantly reduced the number of migratory cells (Fig. 5).

Caudatin treatment decreases expression of $\beta$-catenin. The prominent role of $\mathrm{Wnt} / \beta$-catenin signaling in tumorigenesis has attracted considerable interest in the drug discovery research community, and identification of inhibitors for this signaling pathway has been a goal of researchers. To assess whether caudatin affects the expression of $\beta$-catenin, SMMC-7721 cells were exposed to various concentrations of caudatin for $24 \mathrm{~h}$. Western blot results indicated that caudatin significantly downregulated the expression of $\beta$-catenin which was also associated with a significant decrease in GSK3 $\beta$ levels in SMMC-7721 cells (Fig. 6), suggesting that caudatin regulates the $\beta$-catenin pathway by inducing $\beta$-catenin degradation. In addition, treatment of SMMC-7721 cells with caudatin caused a significant reduction in the level of COX-2, MMP-2, MMP-9 and VEGF, the downstream targets of $\beta$-catenin.

Caudatin suppresses the expression of $\beta$-catenin pathway downstream target genes. Since cox-2, mmp-2 and mmp-9 are the downstream target genes of the Wnt//-catenin pathway 
$\begin{array}{llllll}0 & 12.5 & 25 & 50 & \mu \mathrm{M}\end{array}$

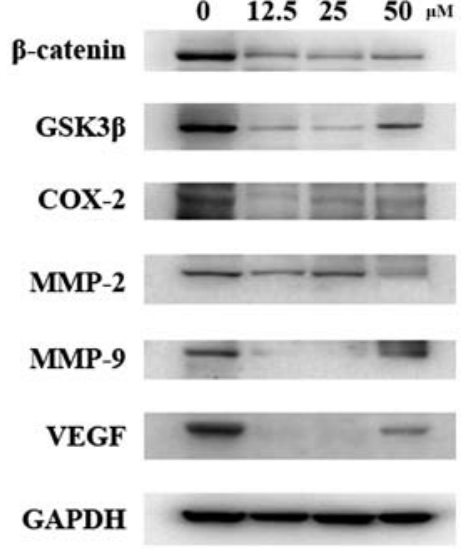

Figure 6. Western blot analysis of Wnt/ $\beta$-catenin pathway-related proteins. Total cell lysates of SMMC-7721 cells treated with or without caudatin at the indicated concentrations for $24 \mathrm{~h}$ were analyzed by SDS-PAGE and, subsequently immunoblotted with antibodies against $\beta$-catenin, GSK3 $\beta$, COX-2, MMP-2, MMP-9, VEGF and GAPDH.

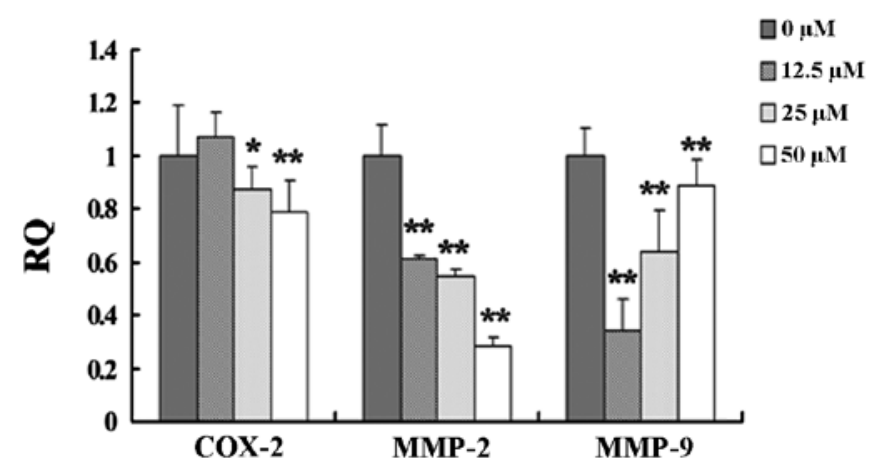

Figure 7. Inhibitory effects of caudatin on the expression of Wnt/ß-catenin downstream genes in SMMC-7721 cells. Cells were treated with caudatin $(12.5,25$ and $50 \mu \mathrm{M})$ for 48 h. Cox-2, $m m p-2$ and $m m p-9$ mRNA expression was evaluated by qRT-PCR. Densitometric analysis of RT-PCR results normalized to GAPDH are shown as a bar graph. Results represent the mean of 3 experiments \pm SD. ${ }^{*} \mathrm{P}<0.05,{ }^{* *} \mathrm{P}<0.01$ vs. control.

(11), we examined whether caudatin downregulates the expression of these genes in SMMC-7721 cells. At the dose range of 12.5-50 $\mu \mathrm{M}$, caudatin was able to inhibit cox-2, mmp-2 and mmp-9 mRNA expression in a dose-dependent manner. The inhibitory effect on $c o x-2$ and $m m p-2$ mRNA expression was positively correlated with the dose of caudatin while $m m p-9$ exhibited a negative correlation (Fig. 7).

\section{Discussion}

Considering the high recurrence and high transfer characteristics of liver cancer, treatment after tumor recurrence and metastasis is a key factor for prolonging survival time. Metastasis and invasion are also important factors affecting the effective treatment of liver cancer. At present, basic research on the metastasis and invasion of liver cancer is ongoing, but no important breakthrough has been reported.

Wnt signaling is an evolutionarily conserved signaling cascade with imperative roles in regulating developmental decisions as well as adult tissue homeostasis. The protein $\beta$-catenin is the central player in one major arm of the Wnt pathway called the canonical Wnt pathway $(12,13)$. Characterization of this pathway has shown that the Wnt/ $\beta$-catenin signaling pathway is indispensible in processes as diverse as cell fate, proliferation, differentiation, growth and cell survival (14-16). Hyperactivation of $\beta$-catenin signaling has been implicated as a driver of various types of cancers, including liver cancer. Invasion and metastasis of malignant tumors depend on angiogenesis. Furthermore, research has found that the $\mathrm{Wnt} / \beta$-catenin signaling pathway plays an important role in angiogenesis. In vivo experiments have demonstrated that a large number of vascular cells express multiple Wnt proteins, such as Wnt-2, Wnt-5a and Wnt receptor FZD. In many developmental and pathological conditions, stable intravascular expression of $\beta$-catenin was found, which further confirmed the regulatory effect of the Wnt/ $\beta$-catenin signaling pathway on angiogenesis (17). Recent studies have shown that MMPs as tumor invasion and metastasis-promoting factors are closely related to the Wnt/ $\beta$-catenin signaling pathway (18). It has been found that HCC tumor angiogenesis, tumor progression and liver metastasis are closely related to the high expression of MMP-2 in patients with a poor prognosis. MMP-2 overexpression causes the degradation of type IV collagen in the extracellular matrix (ECM) and basement membrane (BM) and this may be the main cause of of cell invasion and metastasis of HCC. Arii et al (19) found that MMP-9 gene expression levels can be used as indicators of primary liver cancer recurrence, invasion and metastasis. Vascular endothelial growth factor (VEGF) is a highly specific endothelial mitogen which promotes endothelial cell division, proliferation and induces the occurrence of blood vessels during tumor occurrence and development. Kamel et al (20) found that VEGF expression promotes HCC recurrence, invasion and metastasis. Zhang et al (21) reported on 805 bp upstream of VEGF promoter locus TCF4 binding components, indicating that the Wnt signaling pathway significantly upregulated the expression of VEGF. COX-2 in addition to regulating the expression of MMP, is also involved in tumor angiogenesis. APC mutations can greatly enhance the activity of COX- 2 , indicating that $\mathrm{Wnt} / \beta$-catenin signaling also regulates the expression of $\mathrm{COX}-2$ and promotes tumor angiogenesis.

Caudatin is mainly isolated from the root of Cynanchum bungei Decne, a traditional Chinese medicine and health food, which has been used to nourish the blood and enhance immunity in China and other Asian countries for a long time (10). Recently, other researchers have observed that caudatin induces cell growth arrest and apoptosis in human hepatoma cells. However, the molecular mechanisms are still unclear. In the present study, we used human hepatoma cells as experimental material to confirm the antitumor effect of caudatin, and to illustrate the underlying mechanisms of its anticancer activity. We first examined the cell cycle and cell apoptosis by flow cytometric assay, and found that caudatin induced SMMC7721 cell apoptosis and arrested the cell cycle in the G2 phase. To further investigate the mechanism of caudatin involved in the regulation of cell proliferation and apoptosis, the protein level of $\beta$-catenin was determined by western blot assay. We found that caudatin treatment inhibited the expression of $\beta$-catenin and GSK $3 \beta$. Activation of Wnt signaling by binding of Wnt ligands to a Frizzled receptor inhibits GSK3 $\beta$-mediated phosphorylation of $\beta$-catenin, resulting in an accumulation of 
hypophosphorylated $\beta$-catenin in the cytosol (22). Stabilized hypophosphorylated or dephosphorylated $\beta$-catenin eventually translocates to the nucleus, leading to modulated expression of a broad range of genes, such as cyclin D1 and Myc $(23,24)$. In the present study, we also investigated expression levels of the downstream target genes associated with the Wnt/ $\beta$-catenin pathway. Cox-2, $m m p-2$ and $m m p-9$ mRNA was inhibited by caudatin as a result of its inhibitory effect on $\beta$-catenin and GSK3 $\beta$.

Traditional Chinese medicine with its unique manner of syndrome differentiation and 'preventive treatment of disease' has demonstrated efficiency in the control of tumor metastasis and has received scientific attention and affirmation. Treatment of liver cancer with Chinese medicine offers the advantages of multi-component, multi-link, multi-target effects. A variety of Chinese herbal medicinal ingredients has been proven to play roles in liver cancer through a series of signal transduction pathways; yet, the specific areas in which they interfere with signal transduction remain unclear. Current research has mainly focused on tumor cell proliferation, apoptosis and tumor angiogenesis, as the signal transduction pathway is extremely complex. To elucidate the specific mechanisms of the effects of Chinese medicine on liver cancer, further in-depth study and discussion must be carried out.

\section{Acknowledgements}

The present study was supported by the second part of the Jiangsu Province Outstanding Young Chinese Medical Talents Training Project, Jiangsu Province Administration of Traditional Chinese Medicine (no. YX1214).

\section{References}

1. O'Brien K, Cokkinides V, Jemal A, et al: Cancer statistics for Hispanics, 2003. CA Cancer J Clin 53: 208-226, 2003.

2. Bruix J and Sherman M: Management of hepatocellular carcinoma: an update. Hepatology 53: 1020-1022, 2011.

3. Bruix J, Raoul JL, Sherman M, et al: Efficacy and safety of sorafenib in patients with advanced hepatocellular carcinoma: subanalyses of a phase III trial. J Hepatol 57: 821-829, 2012.

4. Llovet JM, Ricci S, Mazzaferro V, et al: Sorafenib in advanced hepatocellular carcinoma. N Engl J Med 359: 378-390, 2008.

5. Su M, Wu X, Chung HY, Li Y and Ye W: Antiproliferative activities of five Chinese medicinal herbs and active compounds in Elephantopus scaber. Nat Prod Commun 4: 1025-1030, 2009.

6. Chang C, Zhu Y, Tang X and Tao W: The anti-proliferative effects of norcantharidin on human HepG2 cells in cell culture. Mol Biol Rep 38: 163-169, 2011.

7. Lee MK, Yeo H, Kim J, Markelonis GJ, Oh TH and Kim YC: Cynandione A from Cynanchum wilfordii protects cultured cortical neurons from toxicity induced by $\mathrm{H}_{2} \mathrm{O}_{2}$, L-glutamate, and kainate. J Neurosci Res 59: 259-264, 2000.
8. Lee MK, Yeo H, Kim J and Kim YC: Protection of rat hepatocytes exposed to $\mathrm{CCl}_{4}$ in-vitro by cynandione $\mathrm{A}$, a biacetophenone from Cynanchum wilfordii. J Pharm Pharmacol 52: 341-345, 2000.

9. Peng YR, Ding YF, Wei YJ, Shu B, Li YB and Liu XD: Caudatin2,6 -dideoxy-3-O-methy- $\beta$-D-cymaropyranoside 1 induced apoptosis through caspase 3-dependent pathway in human hepatoma cell line SMMC-7721. Phytother Res 25: 631-637, 2011.

10. Zhang JF, Li YB, Li CL and Jiang JQ: Studies on chemical constituents in root tuber of Cynanchum auriculatum. Zhongguo Zhong Yao Za Zhi 31: 814-816, 2006 (In Chinese).

11. Pongracz JE and Stockley RA: Wnt signalling in lung development and diseases. Respir Res 7: 15, 2006.

12. MacDonald BT, Tamai K and He X: Wnt/ $\beta$-catenin signaling: components, mechanisms, and diseases. Dev Cell 17: 9-26, 2009.

13. Behari J: The Wnt/ $\beta$-catenin signaling pathway in liver biology and disease. Expert Rev Gastroenterol Hepatol 4: 745-756, 2010.

14. El Wakil A and Lalli E: The Wnt/beta-catenin pathway in adrenocortical development and cancer. Mol Cell Endocrinol 332: 32-37, 2011.

15. Monga SP: Role of Wnt/ $\beta$-catenin signaling in liver metabolism and cancer. Int J Biochem Cell Biol 43: 1021-1029, 2011.

16. Xiong F, Leonov S, Howard AC, et al: Receptor for advanced glycation end products (RAGE) prevents endothelial cell membrane resealing and regulates $\mathrm{F}$-actin remodeling in a $\beta$-catenin-dependent manner. J Biol Chem 286: 35061-35070, 2011.

17. Goodwin AM and D'Amore PA: Wnt signaling in the vasculature. Angiogenesis 5: 1-9, 2002.

18. Mei JM, Borchert GL, Donald SP and Phang JM: Matrix metalloproteinase(s) mediate(s) NO-induced dissociation of $\beta$-catenin from membrane bound E-cadherin and formation of nuclear beta-catenin/LEF-1 complex. Carcinogenesis 23: 2119-2122, 2002.

19. Arii S, Mise M, Harada T, et al: Overexpression of matrix metalloproteinase 9 gene in hepatocellular carcinoma with invasive potential. Hepatology 24: 316-322, 1996.

20. Kamel L, Nessim I, Abd-el-Hady A, Ghali A and Ismail A: Assessment of the clinical significance of serum vascular endothelial growth factor and matrix metalloproteinase-9 in patients with hepatocellular carcinoma. J Egypt Soc Parasitol 35: 875-890, 2005.

21. Zhang X, Gaspard JP and Chung DC: Regulation of vascular endothelial growth factor by the Wnt and K-ras pathways in colonic neoplasia. Cancer Res 61: 6050-6054, 2001.

22. Baryawno N, Sveinbjornsson B, Eksborg S, Chen CS, Kogner P and Johnsen JI: Small-molecule inhibitors of phosphatidylinositol 3-kinase/Akt signaling inhibit Wnt// -catenin pathway cross-talk and suppress medulloblastoma growth. Cancer Res 70: 266-276, 2010.

23. Tung JN, Chiang CC, Tsai YY, et al: CyclinD1 protein expressed in pterygia is associated with $\beta$-catenin protein localization. Mol Vis 16: 2733-2738, 2010.

24. Zhang JY, Tao LY, Liang YJ, et al: Secalonic acid D induced leukemia cell apoptosis and cell cycle arrest of G(1) with involvement of GSK-3 $/ \beta$-catenin/c-Myc pathway. Cell Cycle 8: 2444-2450, 2009. 